\section{Incentives aim to boost antibiotic development}

Two new incentives launched on both sides of the Atlantic aim to lure companies back into anti-infective drug development. In May, the European Innovative Medicines Initiative (IMI) launched NewDrugs4BadBugs (ND4BB), a project to support the development of new antibiotics. The IMI is contributing $€ 109$ ( $\$ 134)$ million and participating companies will provide $€ 114.7$ (\$140.8) million as in-kind contributions. In the US, the Generating Antibiotic Incentives Now

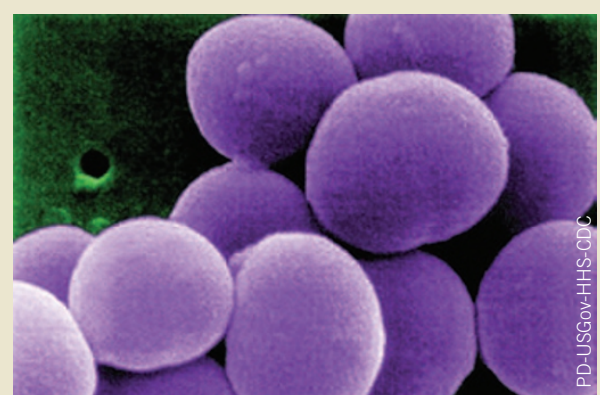

Staphylococcus aureus taken from a vancomycin resistant culture.
(GAIN) Act, incorporated in legislation

to reauthorize the Prescription Drug User Fee Act V (see this issue p733), will take effect in October. The Act provides incentives to stimulate antibiotic drug development, including fast track designation and an additional five-year market exclusivity for new antibiotics that treat a 'qualifying pathogen'.

The need for new compounds to treat the growing problem of antibiotic-resistant infections is urgent. But market failures have led the industry to exit anti-bacterial development. "It's quite natural that a public-private partnership would really need to be built to tackle this important issue," says Michel Goldman, executive director of the IMI, which was set up jointly in 2008 by the European Commission (EC) and the European Federation of Pharmaceutical Industries and Associations (EFPIA). "That's why the EC decided to use the IMI as the public-private partnership that would help to move the antibiotic field forward." The five participating members from the pharmaceutical industry association EFPIA are London-based AstraZeneca, Basilea Pharmaceutica of Basel, London-based GlaxoSmithKline, the Janssen R\&D Unit of Johnson \& Johnson and Paris-based Sanofi.

With ND4BB, the IMI hopes to accelerate antibiotic development not by providing cash but by supporting late-stage trials of pharma-backed compounds. IMI intends to develop a network of clinical investigators who will run the trials and ensure cooperation between industry, academics, hospitals, regulators and patient groups. So far, the initiative has allocated $€ 24$ (\$29) million to preclinical research aimed at drug-resistant Gramnegative bacterial pathogens, and a larger amount to support phase 2 and 3 trials of GSK's GSK1322322, an antibacterial agent that inhibits peptide deformylase function, targeting methicillin-resistant Staphylococcus aureus (MRSA). Also, IMI will be committing an additional €92 (\$112) million for two compounds belonging to AstraZeneca: MEDI4893, an investigational monoclonal antibody that targets a toxin released by $S$. aureus, and AZD9773, a polyclonal ovine Fab fragment directed at tumor necrosis factor alpha for the treatment of severe sepsis and septic shock. ND4BB will establish a European network of clinical centers focusing on trials of drugs to target resistant microbes.

Other companies will participate to a more modest level by openly sharing information on past successes and failures, writes Kenny Simmen, vice-president for virology research at Janssen Infectious Diseases, Research \& Early Development (Belgium). The platform "can improve R\&D efficiency by avoiding redundancy and stimulating synergistic problem solving," adds Anthony Man, CEO of Basilea. He notes that "information that is proprietary to each company is not involved."

In the US, the GAIN Act has been lauded as a "good first step toward addressing the anemic antibiotic pipeline," says Robert Guidos, vice president for public policy and government relations at the Infectious Diseases Society of America in Washington, DC. The most meaningful aspect of the GAIN Act, says Jeffrey Stein, CEO of San Diego-based biotech Trius, is fast track designation for all new compounds to treat qualified pathogens. These include resistant Gram-positive pathogens, such as MRSA, vancomycin-resistant $S$. aureus and vancomycin-resistant Enterococcus; multidrug-resistant Gram-negative bacteria, including Acinetobacter, Klebsiella, Pseudomonas and Escherichia coli; and multidrugresistant tuberculosis. After one year, the GAIN Act would require the agency to examine its guidelines for antibiotics and, if necessary, change them. Guidos adds, "We're waiting to see how far these provisions go to motivate companies to get back into this market."

Josh P Roberts Minneapolis

\section{IN brief}

\section{Gilead/BMS ponder HCV combo}

Gilead Sciences is still deciding whether to combine its antiviral GS-7977 for hepatitis $\mathrm{C}$ virus (HCV) with Bristol-Myers Squibb's daclatasvir in a phase 3 trial, notwithstanding impressive results using the investigational drugs together. The phase 2 data presented in April at the annual meeting of the European Association for the Study of the Liver in Barcelona showed that the all-oral combination achieved early cure rates in $100 \%$ of genotype 1 patients and in $91 \%$ of genotype 2 and 3 patients four weeks after treatment without using interferon Results so far place the GS-7977/daclatasvir combination ahead of the game, however, Bristol's CEO Lamberto Andreotti reportedly said the companies have opposing views on how to proceed. BMS's daclatasvir is a NS5A inhibitor, and Foster City, California-based Gilead already has one of those and is likely to develop its own in-house combination. Gilead's spokesperson Erin Rau says they are currently evaluating the newly released data. "We're going to do that, and look at the best option or options for proceeding as quickly as possible to advance the best all-oral regimen." Gilead gained GS-7977, a nucleotide NS5B polymerase inhibitor, from its $\$ 10.8$ billion acquisition of Princeton, New Jersey-based Pharmasset (Nat. Biotechnol. 30, 122, 2012) and has six other drugs in clinical development for HCV, including phase 2 NS5A inhibitor GS5885. BMS spokesperson Sonia Choi says the New York company is currently working on four other combinations with daclatasvir using its NS5B nucleotide BMS-986094. Karen Carey

\section{Indian Bt cotton discounted}

A producer of genetically modified (GM) cotton from Pune, India, teamed up with a state-run farmers' cooperative to sell its insect-resistant seeds at a much-reduced price. Krishidhan Seeds will market its own cotton varieties developed by incorporating Monsanto's Bacillus thuringiensis $(B t)$ gene into its own hybrids through the Maharashtra State Cotton Growers Marketing Federation, located in Nagpur. The strategic move ensures farmers benefit from the subsidies available to private-public entities. The Maharashtra state accounts for nearly a third of all GM cotton grown in India, and its uptake has been growing since 2002. Critics like Kishore Tiwari of the advocacy group Vidarbha Jan Andolan Samiti in Yavatmal consider the state's support for GM varieties ironic, as this cotton-growing region witnessed the most farmers' suicides since 2005. But an independent investigation conducted in 2009 concluded that suicide among farmers had several causes and $B t$ cotton was not a major factor (Nat. Biotechnol. 27, 9-10, 2009). A recent study tracking 533 smallholder cotton growers in India from 2002 -2008 found that those adopting $B t$ cotton had $24 \%$ higher yields and a $50 \%$ gain in profits compared with farmers growing traditional varieties (http://www.pnas.org/cgi/doi/10.1073/ pnas.1203647109). Killugudi Jayaraman 